\title{
МЕХАНИЗМ РЕАЛИЗАЦИИ СТРАТЕГИИ РАЗВИТИЯ РЕГИОНА С ИСПОЛЬЗОВАНИЕМ КОНЦЕПЦИИ БЕНЧМАРКИНГА
}

\begin{abstract}
АНнотАция. В современных условиях функционирования экономики России формируется потребность в качественном стратегическом управлении регионами. В последнее время широкое распространение получило мнение о том, что именно регионы и города становятся основным субъектом стратегического планирования. Предложено определение стратегии развития региона. Одним из актуальных инструментов реализации стратегии развития региона является бенчмаркинг, суть которого заключается в сравнении составных частей маркетинговых стратегий между территориями и оценке путей оптимального использования ресурсных возможностей. В статье представлено методологическое обеспечение бенчмаркинга, как одного из возможных инструментов реализации стратегии развития региона. Предлагаются пути адаптации регионального бенчмаркинга относительно культурных, политических, экономических и экологических особенностей развития региона. Представлен алгоритм сравнения одной территории с другой для получения сведений о сильных и слабых сторонах, а также о возможности применения успешного опыта.
\end{abstract}

кЛЮчЕВЫЕ СЛОВА. Бенчмаркинг; стратегия развития регионов; программы развития; потенциал стратегии развития; концепция бенчмаркинга; стратегическое планирование.

ИНФОРМАЦИЯ О СТАТЬЕ. Дата поступления 18 мая 2016 г.; дата принятия к печати 3 июня 2016 г.; дата онлайн-размещения 27 июля 2016 г.

A. N. Fedotov Baikal State University, Irkutsk, Russian Federation

\section{MECHANISM OF IMPLEMENTING REGIONAL DEVELOPMENT STRATEGY WITH THE USE OF THE CONCEPT OF BENCHMARKING}

\begin{abstract}
In the current context of Russian economic performance there arises a need for high-quality strategic management of the regions. Recently, a widespread opinion is that it is the regions and cities that are the main subject of strategic planning. The article offers a definition of the regional development strategy. One of the topical tools of implementing the regional development strategy is benchmarking the essence of which is in comparison of constituent elements of marketing strategies between the territories and assessment of ways of optimal use of resource possibilities. The article presents a methodological provision of benchmarking as a possible tool of implementing the regional development strategy. It offers ways of adapting regional benchmarking to cultural, political, economic and ecological features of the regional development. It presents an algorithm of comparing one territory with another one in order to obtain information about strong and week points, as well as the information about using successful experience.

KEYWORDS. Benchmarking; regional development strategy; development programs; development strategy potential; benchmarking concept; strategic planning.

ARTICLE INFO. Received May 18, 2016; accepted June 3, 2016; available online July 27, 2016.
\end{abstract}

Стратегическое планирование социально-экономического развития регионов в современных условиях формирования новой экономической политики Российской Федерации, а также в рамках проводимых реформ остается предметом пристального внимания отечественной науки и практики. Формирование единого механиз-

(C) A. Н. Федотов, 2016

\section{Baikal Research Journal}

электронный научный журнал Байкальского государственного университета 
ма стратегического планирования развития регионов является основой для создания благоприятной среды реализации проектов и программ бизнеса. Стратегия развития региона является главным элементом системы планирования социально-экономического развития. Стратегия необходима для грамотного построения всех составляющих элементов социально-экономического планирования, которые применяются в рамках данной территории, с бюджетным обоснованием реализации предлагаемых процессов [1, с. 5]. Таким образом, стратегия развития региона становится основой социально-экономических отношений субъекта.

Стратегия развития региона призвана выполнять две важные управленческие функции: во-первых, в ходе реализации стратегии выбирается наиболее оптимальный вариант развития региона, учитывающий интересы населения региона и имеющиеся ресурсы и возможности; во-вторых, разрабатывается детальный план действий, позволяющий региону реализовать выбранный вариант.

Стратегии развития региона создают предпосылки для оперативного внесения изменений в объекте регионального управления и окружающей социально-экономической среде. В данном случае речь идет о потенциале стратегии. Для эффективного использования потенциала стратегии развития региона необходимо знать его составляющие элементы и признаки классификации. Кроме того, требуется разработать механизм оценки каждого элемента с применением показателей как количественного, так и качественного плана. В целях грамотного анализа стратегии развития региона важно также определить степень влияния на потенциал различных событий социального, экологического и экономического характера.

Потенциал стратегии развития региона определяется рядом характеристик, которые создают возможности для осуществления предусмотренных планами трансформаций социально-экономического состояния. Процесс формирования потенциала во многом зависит от состояния ресурсной базы исследуемого региона. Под ресурсной базой понимается наличие на данной территории историко-культурных, трудовых, интеллектуальных и материальных ценностей [2, с. 123].

Надо отметить, что в настоящее время недостаточно полно используется потенциал регионального маркетинга. Маркетинг регионов представляет собой основополагающий элемент, который призван играть решающую роль при формировании и реализации стратегии развития территории. Сама концепция регионального маркетинга направлена на поддержку и привлечение инвестиционных потоков, которые позволят положительно изменить состояние региона с точки зрения инновационно-инвестиционной деятельности [3, с. 56]. В этой связи важнейшим для государственных организаций регионального уровня является разработка и применение передовых управленческих технологий, позволяющих эффективно использовать имеющиеся у региона ресурсы. Возникла необходимость применения таких инновационных методов и инструментов, которые позволят сформировать эффективную систему регионального управления, достичь поставленных стратегических целей и соответствовать современным требованиям национальной экономики.

В настоящее время возникла необходимость активного взаимодействия региональных государственных институтов по обмену передовым опытом, знаниями и технологиями в области государственного регионального управления. Использование передовых управленческих технологий, успешно применяемых в других регионах России, позволит существенным образом повысить эффективность деятельности государственных органов управления и сформировать благоприятную среду для функционирования подведомственных им государственных учреждений: образование, здравоохранение, социальная защита, культура и т. д. Кроме того, использование инновационных управленческих технологий благоприятно скажется и на развитии региональной бизнес-среды, а значит, и на условиях жизни граждан региона.

\section{Baikal Research Journal}

электронный научный журнал Байкальского государственного университета 
Вопросы повышения конкурентоспособности региона и улучшения территориальной привлекательности не раз поднимались в трудах известных ученых экономистов. Причем среди критериев выбора региона в рамках территориальной привлекательности предлагались не только хорошие климатические условия, природа и туристические достопримечательности, но и развитая инфраструктура, производство, услуги и система распределения, в том числе розничная и оптовая торговля. Данный аспект рассматривали в своих научных трудах такие ученые, как В. С. Колодин и Н. Г. Новикова $[4 ; 5$, с. 63$]$.

На наш взгляд, для эффективного решения поставленных задач можно использовать концепцию бенчмаркинга, который оценивает качественные характеристики товара не с точки зрения его эксплуатационных свойств и технических характеристик, а с точки зрения степени удовлетворения потребностей покупателей в ходе его применения [6, с. 139]. Сущность концепции бенчмаркинга заключается в выявлении, систематизации и анализе передовой информации и инновационного опыта деятельности ведущих организаций для их последующего использования в своей компании. Причем следует помнить, что бенчмаркинг - это не разовое эпизодическое мероприятие. Использование концепции бенчмаркинга подразумевает регулярное проведение мероприятий по обмену и управлению знаниями и опытом в целях повышения эффективности деятельности организации на всех звеньях управления [7, с. 7].

По мнению известных консалтинговых компаний, бенчмаркинг лидирует и входит в пятерку эффективнейших методов управления, апробированных на опыте известных компаний. Недостаточно полное использование современного механизма бенчмаркинга может привести к тому, что руководители и специалисты не могут эффективно применить полученные передовые знания, опыт и инновации, которые могли бы улучшить результаты деятельности компании [8, с. 23]. Передовой опыт и инновационные технологии в области управления на всех уровнях являются основной составляющей интеллектуального капитала, ценность которого и может значительно превосходить материальный капитал.

Необходимо отметить такой важный фактор, как систематичность взаимодействия обмена передовым опытом, знаниями, технологиями и инновациями и их осуществление на всех уровнях управления $[9$, с. 6]. В целях адаптации технологии бенчмаркинга применительно к реализации стратегии развития региона необходимо представить следующий алгоритм использования данной технологии:

- 1 этап - всестороннее и детальное изучение лучших достижений регионов-лидеров, территориально расположенных не только в рамках национального государства, но и на внешних рынках;

- 2 этап - систематическое изучение и выявление слабых сторон деятельности субъектов региона в области производственных и организационных технологий, и в первую очередь, технологий государственного управления;

- 3 этап - применение передовых управленческих технологий и опыта на уровне своего субъекта с учетом адаптации относительно социо-культурных, экономических, политических, природно-климатических, научно-технических и демографических особенностей развития региона.

Таким образом, бенчмаркинг - концепция, предполагающая и стимулирующая интересы институтов управления к постоянному поиску и совершенствованию инноваций в области регионального менеджмента, с их последующей адаптацией и использованию в системе управления регионом, в том числе при формировании стратегии развития [10, с. 106].

В качестве доказательства можно предложить ряд утверждений в пользу бенчмаркинга.

\section{Baikal Research Journal}

электронный научный журнал Байкальского государственного университета 
Во-первых, успешный опыт применения концепции бенчмаркинга в рамках решения проблем территориального развития, в том числе и на региональном уровне (пример развития Калужской, Владимирской и Кемеровской областей).

Во-вторых, стратегия развития региона как товар обладает как количественными, так и качественными характеристиками. Как и любой товар, стратегия развития переживает все стадии жизненного цикла (от разработки до спада), что предполагает управление данным товаром на всех этапах его развития.

B-третьих, бенчмаркинг позволяет органам регионального управления использовать передовой опыт в области государственного менеджмента, а также имеющийся у них ресурс административных методов регулирования для того, чтобы повысить уровень конкурентоспособности региона за счет создания механизма заинтересованности субъектов хозяйствования в достижении более высокого качества выпускаемых товаров и услуг.

B-четвертых, основной целью развития территории является обеспечение высокого уровня качества жизни в регионе по сравнению с другими территориальными субъектами с ориентацией на мировые стандарты, сохраняя при этом высокий уровень привлекательности региона.

В связи с чем необходимо подчеркнуть, что акцент на качество жизни должен быть сделан не с позиций межрегиональной конкурентной борьбы, а как результат повышения уровня удовлетворенности жителей. Бенчмаркинг - это метод, который позволяет при разработке стратегии развития региона ориентироваться не на прошлые тенденции, а учитывать современные требования мирового стандарта [11, с. 84].

В целях совершенствования системы стратегического планирования социально-экономического развития г. Иркутска, руководствуясь Федеральным законом «Об общих принципах организации местного самоуправления в Российской Федерации" от 6 октября 2003 г. № 131-ФЗ, Думой г. Иркутска 5 июля 2012 г. была одобрена Стратегия социально-экономического развития города до 2025 года ${ }^{1}$. Правительством Иркутской области был принят документ, регламентирующий реализацию стратегии социально-экономического развития Иркутской области на долгосрочный период. Основной стратегической целью социально-экономического развития Иркутской области и г. Иркутска является повышение уровня и качества жизни в Иркутской области путем роста конкурентоспособности области на основе изменения структуры региональной экономики. В данных документах достаточно грамотно представлены все составляющие маркетингового анализа с указанием сильных и слабых сторон развития отдельных направлений региональной экономической политики. Указаны осложнения и угрозы экономического развития, а также разработан механизм по преодолению данных угроз. Однако при разработке плана стратегического развития города и области на учтены передовые технологии в области регионального управления, применяемые другими субъектами Российской Федерации.

В целях эффективного использования механизма бенчмаркинга для формирования качественной стратегии развития рассматриваемого региона необходимо реализовать ряд мероприятий, позволяющих грамотно и безболезненно применить передовые управленческие технологии, успешно внедряемые другими регионами:

- организовать постоянный мониторинг происходящих изменений в экологической и социокультурной среде, которые оказывают влияние как на концепцию

1 URL : https://www.google.ru/url?sa=t\&rct=j\&q=\&esrc=s\&source=web\&cd=1\&ved=0ahUKEwj2Nv7jIPOAhUFfiwKHccFDLYQFggbMAA\&url=http $\% 3 \mathrm{~A} \% 2 \mathrm{~F} \% 2 \mathrm{Fadmirk} . \mathrm{ru} \%$ 2FDocLib $\%$ 2F $\%$ 25D0 $\% 2$ $5 \mathrm{~A} 1 \% 25 \mathrm{D} 1 \% 2582 \% 25 \mathrm{D} 1 \% 2580 \% 25 \mathrm{D} 0 \% 25 \mathrm{~B} 0 \% 25 \mathrm{D} 1 \% 2582 \% 25 \mathrm{D} 0 \% 25 \mathrm{~B} 5 \% 25 \mathrm{D} 0 \% 25 \mathrm{~B} 3 \% 25 \mathrm{D} 0 \% 25$ $\mathrm{B} 8 \% 25 \mathrm{D} 1 \% 258 \mathrm{~F} \% 2520 \% 25 \mathrm{D} 0 \% 2598 \% 25 \mathrm{D} 1 \% 2580 \% 25 \mathrm{D} 0 \% 25 \mathrm{BA} \% 25 \mathrm{D} 1 \% 2583 \% 25 \mathrm{D} 1 \% 2582 \% 25 \mathrm{D}$ $1 \% 2581 \% 25 \mathrm{D} 0 \% 25 \mathrm{BA} \% 2520(\% 25 \mathrm{D0} \%$ 25BE $\%$ 25D1\% 2582\% 252005.05.2015).pdf\&usg=AFQjCNFuo5 HSqleGY9PEL2ckDAxRPe-iLg\&bvm=bv.127521224,d.bGg.

\section{Baikal Research Journal}

электронный научный журнал Байкальского государственного университета 
качества управленческих услуг, предоставляемых региональными органами управления, так и на систему контроля их качества;

- создать эффективный механизм, обеспечивающий процесс постоянного совершенствования регионального менеджмента и производимых на его территории товаров и услуг;

- разработать механизм обеспечения ориентации системы управления на потребности населения региона и других функционирующих на его территории субъектов хозяйствования;

- сформировать мотивационную систему стимулирования, при которой все субъекты хозяйствования на данной территории были бы заинтересованы в высоком качестве выпускаемых продуктов и услуг;

- разработать шкалу персональной ответственности управленческого звена высшего эшелона власти за реализацию концепции бенчмаркинга в области управления регионом, в том числе за качество реализации стратегии развития;

- постоянно вести сопоставление между намеченными целями и задачами в области управления и издержками, необходимыми для поддержки достаточного уровня качества жизни в регионе;

- периодически отслеживать осложнения и угрозы со стороны бизнес-среды и внешних макрофакторов и принимать меры для их преодоления или смягчения негативных последствий;

- обеспечить постоянный контроль и аудит применяемых систем управления качеством.

Внедрение концепции бенчмаркинга - это деятельность не отдельных индивидов или субъектов предпринимательства, а всего регионального социума. Руководство региона должно осознавать, что подготовка к внедрению данной системы предполагает необходимость объединения всех участников территориального маркетинга в целях достижения целей региона и реализации стратегии развития. Важным фактором эффективности применения бенчмаркинга является постоянство слежения за тем, чтобы проводимая политика была понята и поддержана всеми участниками системы управления регионом [12, с. 58].

Основа бенчмаркинга - это удовлетворенность участников процесса применения данной системы, поэтому для достижения успеха в развитии региона необходимо отчетливое понимание того, какие потребительские цели преследуют потребители, определение их потребностей и ожиданий. В то же время необходимо сконцентрировать внимание каждого участника процесса на том, что любой из них выступает одновременно в роли потребителя и в роли поставщика, поскольку получает ресурсы (информационные, материальные, финансовые и управленческие) от одних, а результаты своего труда отдает другим. Даже небольшой сбой в системе влияет на качество конечного продукта. Таким образом, каждый субъект хозяйствования, функционирующий в данном регионе, выполняет четкие определенные функции в процессе реализации стратегии развития.

Бенчмаркинг - ключ к постоянному улучшению производственных и управленческих технологий как на региональном уровне, так и на уровне отдельных предприятий и организаций. Это не только механизм сбора и обработки передовой информации и опыта в области эффективного управления, но и инструмент регионального менеджмента, используемый для выявления возможностей самосовершенствования и определения объектов и субъектов регионального рынка, нуждающихся в совершенствовании. Бенчмаркинг стимулирует непрерывность процесса совершенствования в целях повышения конкурентного статуса региона и его привлекательности как на внутреннем, так и внешнем рынках.

\section{Baikal Research Journal}

электронный научный журнал Байкальского государственного университета 


\section{Список использованной литературы}

1. Червяков С. С. Стратегическое развитие регионов на основе бенчмаркинга и управления конфликтом интересов целевых аудиторий : автореф. дис. ... канд. экон. наук : 08.00.05 / С. С. Червяков. - М., 2012. - 29 с.

2. Котлер Ф. Маркетинг для государственных и общественных организаций / Ф. Котлер, Н. Ли ; пер. с англ. под ред. С. Г. Божук. - СПб. : Питер, 2008. - 384 с.

3. Котлер Ф. Маркетинг. Менеджмент. Анализ, планирование, внедрение, контроль : пер. с англ. / Ф. Котлер, К. Келлер. - 11-е изд. - СПб. : Питер Ком, 2009. — 800 с.

4. Колодин В. С. Направления взаимодействия маркетинговых и логистических технологий в производстве и физическом распределении продукции [Электронный ресурс ] / В. С. Колодин // Известия Иркутской государственной экономической академии (Байкальский государственный университет экономики и права). — 2011. - № 5. - Режим доступа : http:// brj-bguep.ru/reader/article.aspx $? \mathrm{id}=9702$.

5. Новикова Н. Г. Процессный подход к конкурентной стратегии в сфере услуг (на примере розничной торговли) / Н. Г. Новикова // Известия Иркутской государственной экономической академии. - 2014. - № 2 (94). - С. 63-70.

6. Гаврилов А. И. Региональная экономика и управление : учеб. пособие / А. И. Гаврилов. - М. : Юнити-Дана, 2012. - 239 с.

7. Бухвальд Е. М. Субъекты Федерации в системе стратегического планирования / Е. М. Бухвальд // Вестник Российской академии естественных наук. - 2015. - № 2. C. $7-10$.

8. Панкрухин А. П. Территориальный маркетинг / А. П. Панкрухин // Маркетинг в России и за рубежом. - 2010. - № 7. - С. 23-24.

9. Тычинская И. А. Формирование регионального маркетинга : автореф. дис. ... канд. экон. наук : 08.00.05 / И. А. Тычинская. - М., 2008. -29 с.

10. Максимова И. В. Использование технологии бенчмаркинга для оценки инновационности целевой программы социально-экономического развития региона / И. В. Максимова // Креативная экономика. - 2011. — № 4 (52). - С. 106-114.

11. Фролов Д. П. Маркетинговая парадигма стратегического территориального менеджмента / Д. П. Фролов, В. А. Шишов // Менеджмент и бизнес-администрирование. - 2013. № 2. - С. 84-96.

12. Бурак П. Формирование системы стратегического планирования на региональном уровне / П. Бурак // Проблемы теории и практики управления. — 2014. — № 11. — C. $58-64$.

\section{References}

1. Chervyakov S. S. Strategicheskoe razvitie regionov na osnove benchmarkinga i upravleniya konfliktom interesov tselevykh auditoria. Avtoref. Kand. Diss. [Regional strategic planning on the basis of benchmarking and managing conflict interests of target audiences. Cand. Diss. Thesis]. Moscow, 2012. 29 p.

2. Kotler Philip, Lee Nancy. Marketing dlya gosudarstvennykh i obshchestvennykh orga nizatsii [Marketing for governmental and public organizations]. Saint Petersburg, Piter Publ., 2008. 384 p.

3. Kotler Philip, Keller Kevin Lane. Marketing. Management. Prentice Hall, 2000. 813 p. (Russ. ed.: Kotler F., Keller K. Marketing. Menedzhment. Analiz, planirovanie, vnedrenie, kontrol. $11^{\text {th }}$ ed. Saint Petersburg, Piter Publ., 2009. 800 p.).

4. Kolodin V. S. Interaction of marketing and logistics technologies in production and product distribution. Izvestiya Irkutskoy gosudarstvennoy ekonomicheskoy akademii (Baykalskiy gosudarstvennyy universitet ekonomiki i prava) = Bulletin of Irkutsk State Economics Academy (Baikal State University of Economics and Law), 2011, no. 5. Available at: http://brj-bguep.ru/ reader/article.aspx?id=9702. (In Russian).

5. Novikova N. G. The process approach to competitive strategy in the service sector (on the example of retailing). Izvestiya Irkutskoy gosudarstvennoy ekonomicheskoy akademii = Bulletin of Irkutsk State Economics Academy, 2014, no. 2 (94), pp. 63-70. (In Russian).

6. Gavrilov A. I. Regional'naya ekonomika i upravlenie [Regional economy and management]. Moscow, Yuniti-Dana Publ., 2012. 239 p.

\section{Baikal Research Journal}


7. Bukhvald E. M. Federation entities in strategic planning system. Vestnik Rossiiskoi akademii estestvennykh nauk = Bulletin of the Russian Academy of Natural Sciences, 2015, no. 2, pp. 7-10. (In Russian).

8. Pankrukhin A. P. Territorial marketing. Marketing $v$ Rossii i za rubezhom $=$ Marketing in Russia and Abroad, 2010, no. 7, pp. 23-24. (In Russian).

9. Tychinskaya I. A. Formirovanie regional'nogo marketinga. Avtoref. Kand. Diss. [Developing regional marketing. Cand. Diss. Thesis]. Moscow, 2008. 29 p.

10. Maksimova I. V. Using benchmark technology for assessing innovativeness of target program for regional socio-economic development. Kreativnaya ekonomika = Journal of Creative Economy, 2011, no. 4 (52), pp. 106-114. (In Russian).

11. Frolov D. P., Shishkov V. A. Marketing paradigm of strategic territorial management. Menedzhment $i$ biznes-administrirovanie = Management and Business Administration, 2013, no. 2, pp. 84-96. (In Russian).

12. Burak P. Developing strategic planning system at regional level: Scientific and Methodological Support. Problemy teorii i praktiki upravleniya = Problems of Theory and Practice of Management, 2014, no. 11, pp. 58-64. (In Russian).

\section{Информация об авторе}

Федотов Андрей Николаевич - кандидат экономических наук, доцент, кафедра логистики и коммерции, Байкальский государственный университет, 664003, г. Иркутск, ул. Ленина, 11, e-mail: fedotov_an@rambler.ru.

\section{Author}

Andrey N.Fedotov - PhD in Economics, Associate Professor, Chair of Logistics and Commerce, Baikal State University, 11 Lenin St., 664003, Irkutsk, Russian Federation; e-mail: fedotov_an@rambler.ru.

\section{Библиографическое описание статьи}

Федотов А. Н. Механизм реализации стратегии развития региона с использованием концепции бенчмаркинга / А. Н. Федотов // Baikal Research Journal. — 2016. — T. 7, № 4. DOI : $10.17150 / 2411-6262.2016 .7(4) .12$.

\section{Reference to article}

Fedotov A. N. Mechanism of implementing regional development strategy with the use of the concept of benchmarking. Baikal Research Journal, 2016, vol. 7, no. 4. DOI : 10.17150/24116262.2016.7(4).12. (In Russian).

\section{Baikal Research Journal}

